\section{Reestruturação produtiva, impactos na saúde e sofrimento mental: o caso de um banco estatal em Minas Gerais, Brasil}

\author{
Economic restructuring and impacts on health and \\ mental distress: the case of a state-owned bank in \\ Minas Gerais State, Brazil
}

\author{
${ }^{1}$ Faculdade de Medicina, \\ Universidade Federal \\ de Minas Gerais, \\ Belo Horizonte, Brasil. \\ 2 Instituto de Ciências Exatas, \\ Universidade Federal de \\ Minas Gerais, Belo Horizonte, \\ Brasil. \\ Correspondência \\ L. S. Silva \\ Departamento de Medicina \\ Preventiva e Social, \\ Faculdade de Medicina, \\ Universidade Federal de \\ Minas Gerais. \\ Av. Prof. Alfredo Balena 190, \\ Belo Horizonte, $M G$ \\ 30130-100, Brasil. \\ luizsergios@yahoo.com.br
}

\begin{abstract}
Restructuring of the Brazilian financial sector was consolidated through the combination of mass lay-offs, automation, and outsourcing, in addition to business reengineering with leveling of hierarchical echelons, labor casualization, and multi-function jobs. In order to comply and deal with the new demands, bank employees had to increase their schooling, become multifunctional and expert sales attendants, and submit to substandard conditions in the workplace, increased workload, overtime, and low wages. The purpose of the current study was to examine the restructuring process in a state-owned bank in Minas Gerais State, Brazil, and its impacts on workers' health. The study also analyzes absenteeism rates from 1998 to 2003, when there was an increase in diseases such as repetitive stress injury (RSI)/work-related musculoskeletal disorders (WRMD) and mental/behavioral disorders, accounting for $56 \%$ and $19 \%$ of sick leaves. The process has continued to the present, with a restrictive recruitment policy. Further study is needed to confirm the results.
\end{abstract}

Cumulative Trauma Disorders; Occupational Health; Mental Health
Luiz Sérgio Silva ${ }^{1}$

Tarcísio Márcio Magalhães Pinheiro 1

Emília Sakurai 2

\section{Introdução}

Este trabalho teve como objetivo avaliar o processo de reestruturação produtiva em um grande banco estatal no Estado de Minas Gerais, Brasil, e seus possíveis impactos na saúde de seus trabalhadores.

Grandes transformações ocorreram no capitalismo recente no Brasil, particularmente na década de 1990, quando, com o advento do receituário e da pragmática neoliberais, desencadeou-se uma grande onda de desregulamentações nas mais distintas esferas do mundo do trabalho, conhecida como reestruturação produtiva 1.

Houve também, como conseqüência dessa reestruturação e do redesenho da divisão internacional do trabalho e do capital, um conjunto de transformações no plano da organização sócio-técnica da produção, num período marcado pela mundialização, transnacionalização e financeirização dos capitais, que certamente reconfiguraram o universo produtivo, industrial e de serviços ${ }^{1}$. Na década de 90 , os sinais de desestruturação do mercado de trabalho assumiram maior destaque, consolidando a tendência de redução do nível de emprego formal 2 .

A busca pelo modelo acumulação flexível se apoiou na maleabilidade dos processos de trabalho, dos produtos e padrões de consumo. Como conseqüência dessa nova fase de acumulação, a mão-de-obra tem se tornado cada vez mais bara- 
ta e os trabalhadores têm se sujeitado a cargas de trabalho cada vez maiores 3 .

Segundo o Departamento Intersindical de Estatística e Estudos Socioeconômicos (DIEESE) 4, no sistema financeiro brasileiro a intensificação do processo de reestruturação se deu mais tarde, no final da década de 80 e no início dos anos 90, estendendo-se até os dias atuais. Ele elegeu como eixo principal o trinômio demissões em massa, automação e terceirização, sendo a utilização destas estratégias correspondente a momentos diferenciados do ajuste estrutural implementado pelos bancos. Nos bancos estatais, nota-se, além do trinômio anterior, a estagiarização de funções anteriormente exercidas pelos bancários.

A primeira fase da reestruturação produtiva no setor veio com a grande onda de demissões ocorridas logo após a implantação do Plano Cruzado 1. Paralelamente às demissões, os bancos passaram a investir maciçamente em automação e informática, visando à redução de custos operacionais e agilização do atendimento. A segunda fase veio com o Plano Collor I, com nova onda de demissões. Acentuou-se também o processo de automação, que se concentrou no auto-atendimento.

$\mathrm{Na}$ fase mais recente, correspondente à terceirização, os bancos objetivaram enxugar suas estruturas operacionais e redefinir seu perfil de negócios, criando novos produtos e serviços, segmentando mercados e clientela e desenhando as futuras tendências de sua atuação empresarial, seguindo um percurso semelhante ao de outros ramos da economia 5 .

Os bancos, além das demissões em massa da primeira fase de ajustes, incrementaram a automação e investiram na reestruturação administrativa e nos métodos de reengenharia empresarial, como redução dos níveis hierárquicos, flexibilização e polivalência de funções 6 .

Para o DIEESE 7, o ajuste produtivo iniciado com o Plano Cruzado teve impactos profundos sobre a categoria dos bancários, no sentido de redução dos postos de trabalho e da mudança no perfil da categoria. O bancário se tornou polivalente e, principalmente, um exímio vendedor ${ }^{8}$. A categoria bancária distingue-se há muito tempo de outras categorias profissionais no Brasil por ser altamente escolarizada. Nesse panorama de reestruturação, cresce o número de bancários com terceiro grau e decresce a porcentagem daqueles com apenas o primeiro e segundo graus. Os índices de escolaridade mais elevados registrados nos bancos referem-se não a uma exigência do conteúdo próprio ao trabalho, mas a um longo processo de desemprego, que possibilita a permanência no emprego daqueles mais escolarizados 9. Nessa empresa bancária, aproxima- damente $42 \%$ dos trabalhadores possuem curso superior completo contra apenas $32 \%$ daqueles que detêm apenas o ensino médio.

A seqüência de planos de modernização organizacional, tecnológica e administrativa implementados na segunda metade dos anos 90 complementou os programas de ajustes que previam uma eficiente utilização da força de trabalho através de medidas como: relocação de trabalhadores considerados em excesso nas dependências, incentivo a aposentadorias e licenças-interesse e programas de demissão no interesse do serviço e incentivada 10 .

Nesse cenário, os bancários são compelidos a desenvolver uma formação geral e polivalente, na tentativa de manter seus vínculos de trabalho, sendo submetidos à sobrecarga de tarefas e a jornadas de trabalho extenuantes 1 . Os trabalhadores bancários são constrangidos a tornarem-se "parceiros", "sócios", “colaboradores” dos bancos e das instituições financeiras, num ideário e numa pragmática que aviltam ainda mais a condição laborativa ${ }^{10}$. Agravaram-se os problemas de saúde dos trabalhadores, sendo observado nas últimas décadas um aumento sem precedentes de doenças como os distúrbios osteomusculares relacionados ao trabalho (DORT) e os transtornos mentais e comportamentais $9,11,12$.

No contexto que conjuga intensa reestruturação no sistema financeiro internacional e nos sistemas bancários nacionais com formações produtivas que agravam e aperfeiçoam a exploração capitalista do trabalho, os bancários vivem de modo singular a instabilidade do emprego e a intensificação do trabalho. Para Grisci \& Bessi 13, no trabalho bancário, uma lógica de instabilidade e imprevisibilidade resultante das contínuas reestruturações do trabalho, aliadas às novas tecnologias, fez com que o trabalho, em especial nas instituições financeiras estatais, antes tido como trabalho para a vida toda, adquirisse caráter de transitoriedade.

\section{Material e métodos}

Foi realizado um estudo transversal, descritivo e quantitativo abordando absenteísmo e prevalência de causas de afastamento por licenças-saúde em um banco estatal no Estado de Minas Gerais, no período de 1998 a 2003. O estudo foi aprovado pelo Comitê de Ética em Pesquisa da Universidade Federal de Minas Gerais em 5 de agosto de 2004, sob o parecer no. 2 ETIC 042/04.

Trata-se de uma grande empresa do setor bancário, com dependências espalhadas por todo o país. Possuía, no final do estudo em 2003, no Estado de Minas Gerais, 7.499 funcionários, 492 
dependências (58 localizadas na cidade de Belo Horizonte e o restante espalhado pelas demais cidades do estado).

Os dados sobre afastamentos foram fornecidos pela Caixa de Assistência dos funcionários desse banco, que é uma empresa terceirizada responsável pela realização do programa de controle médico de saúde ocupacional do mesmo. Todos os afastamentos por licença-saúde são apresentados a essa caixa, que realiza a avaliação da pertinência, registro, comunicação e estatística. Os afastamentos registrados foram disponibilizados aos pesquisadores sob a forma de arquivo no formato Access (Microsoft Corp., Estados Unidos), contendo nome e matrícula do trabalhador, local de trabalho, período de afastamento e Classificação Estatística Internacional de Doenças e Problemas Relacionados à Saúde, $10^{a}$ Revisão (CID-10) 14. A seguir, esses dados foram agrupados às informações sócio-demográficas obtidas no sistema de recursos humanos da empresa, para a realização da análise estatística.

Adotou-se o conceito de absenteísmo de causa médica da Organização Internacional do Trabalho (OIT) 15, ou seja, o período de ausência laboral que se aceita como atribuível a uma incapacidade do indivíduo, exceção feita para aquela derivada de gravidez normal ou prisão. Entendese por ausência laboral o período ininterrupto de falta ao trabalho, contado desde seu começo, independentemente de sua duração.

Realizou-se também uma pesquisa documental nesse banco entre 1993 e 2003 e, a seguir, uma análise crítica da reestruturação produtiva no mesmo, procurando-se elaborar um traçado histórico, argumentando sobre possíveis fatos e ocorrências que poderiam de alguma forma ter interferido nas mudanças observadas no perfil do absenteísmo do banco neste período. Conhecendo-se o absenteísmo em um dado setor, teremos possíveis indicadores da relação causal e de seus efeitos deletérios à saúde dos trabalhadores, das mudanças tecnológicas e organizacionais implementadas nos locais de trabalho.

O absenteísmo por licença de saúde e a prevalência de afastamentos, entre os anos de 1998 e 2003, foram abordados por grupamentos da CID-10 14, sendo discriminados por doenças específicas os transtornos mentais e comportamentais, um dos destaques em termos de dias perdidos e em número de ocorrências (grupamentos V). O denominador usado para o cálculo das prevalências de afastamentos foi a população de trabalhadores existente ao fim de cada ano considerado. Um trabalhador pode ter apresentado mais de um evento de afastamento.

\section{Resultados}

No período compreendido entre 1993 e 2003, avaliou-se o absenteísmo dos trabalhadores de um grande banco estatal e, a partir da análise de documentação existente na empresa, constatouse a ocorrência de processos de reestruturação produtiva, bem como a forma adotada para sua instalação.

O primeiro grande programa de adequação de quadros na empresa procurava reestruturar os chamados Centros de Processamento de Serviços (CESEC) e a mudança principal era a terceirização dos serviços, sob o argumento de que não exigia qualificação para sua execução e de que os funcionários deveriam estar nas agências prestando um bom serviço à população. Esse argumento foi descrito no Projeto Novo Rosto da empresa, em 1988. Esse projeto foi implementado no decorrer da década de 1990. Existia mais de 140 desses centros em todo o país. Em Minas Gerais, eram em número de nove. Foram todos fechados e os funcionários realocados nas agências ou demitidos, quando não houve condições de aproveitamento local.

Outro grande programa de adequação iniciou-se no dia 28 de junho de 1995, com o anúncio do Programa de Desligamento Voluntário (PDV), e já no dia 31 de julho de 1995, ao seu final, haviam sido homologadas 13.388 rescisões de contratos de trabalho. O objetivo inicial era demitir 16.500 trabalhadores em um mês. Dos 120 mil trabalhadores, 55 mil receberam a comunicação de que eram elegíveis para a adesão ao plano, juntamente com uma planilha de cálculos dos valores que poderiam receber. Havia, no documento entregue a cada trabalhador, uma frase que representava bem a idéia por trás desse plano de desligamento: "Aceitar o desligamento pode viabilizar a realização de um sonho. Encare o programa dessa forma".

$\mathrm{O}$ aprofundamento do processo se deu com o Plano de Adequação de Quadros (PAQ), iniciado em 31 de julho de 1995 e que se estendeu até 1998, quando a redução chegou a mais de 50 mil trabalhadores em todo o país. Nesse segundo plano, os funcionários eram chamados transferíveis e, apesar de critérios terem sido estabelecidos, como tempo de banco, estado civil, se estudante ou não, entre outros, prevaleceu a subjetividade nas decisões das administrações quanto à escolha daqueles que seriam transferidos ou demitidos. Também se estabeleceram condições inferiores àquelas oferecidas inicialmente aos elegíveis no PDV.

A agressividade do processo nesse banco é exemplificada pelo curto período em que transcorreu. No PAQ, o funcionário considerado ex- 
cedente deveria, em uma semana, escolher nova localização, pedir demissão ou aguardar que a própria empresa o fizesse.

Um exemplo desse processo é o caso em que um funcionário do Estado do Acre, considerado excedente, deveria escolher uma nova localização numa cidade mais próxima. Nesse caso, seriam os estados de Roraima, Amapá ou Distrito Federal, os mais próximos, todos distando aproximadamente $2.000 \mathrm{~km}$ de sua localização original.

No caso do Estado de Minas Gerais, conforme os dados elaborados com base em informações do sistema do próprio banco, havia um excedente de 1.175 trabalhadores e apenas 77 vagas na Unidade Federativa. Os trabalhadores iniciaram, então, uma longa peregrinação à procura de locais para trabalhar. Como exemplo, cita-se o caso de um grupo de trabalhadores que, com o fechamento do chamado CESEC Divinópolis, deslocava-se diariamente cerca de $120 \mathrm{~km}$ entre Belo Horizonte (capital do estado) e a cidade de Divinópolis para trabalhar e não serem demitidos. Desse grupo, um trabalhador foi acompanhado em particular. Ele teve diversos afastamentos inicialmente por DORT/LER (lesão por esforço repetitivo), vindo a ser definitivamente aposentado por invalidez em 2004 por transtorno mental e comportamental.

As políticas de recursos humanos dessa empresa em estudo, basicamente se direcionaram para a redução do quadro de trabalhadores durante o longo período que se iniciou na metade da década de 90, estendendo-se até o início de 1998. Porém, acredita-se que esse processo se prolonga até os dias atuais, com a manutenção de uma política restritiva, com ajustes constantes dos quadros das agências e de outras dependências.

Constatou-se, também, uma política de simples reposição de demitidos, aposentados e outras formas de afastamentos. Após longo período de desligamentos e dois planos de adequação de quadros que enxugaram o contingente de trabalhadores, saiu em 1999 o primeiro edital de concurso para o banco pós-reestruturação. Nesse concurso foram aprovados 11.211 candidatos para o Estado de Minas Gerais, dos quais apenas 2.648 tomaram posse. Dos aprovados, 7.702 não foram aproveitados até o final do prazo de validade do concurso, no ano de 2003, e 861 foram excluídos por diversos motivos (inaptidão, desistência, cancelamento por decurso de prazo etc.). Outro concurso ocorreu somente em 2003, nos mesmos moldes do anterior.

No período de 1999 a 2003, aconteceram em Minas Gerais 1.732 desligamentos, o que resultou num acréscimo de aproximadamente 35\% do contingente de trabalhadores, ou seja, 916 .
Quanto aos demais, foram apenas substituições de trabalhadores desligados, configurando-se uma política bem consistente de redução de postos de trabalho, tendo em vista a grande redução de quadros ocorrida entre 1995 e 1998. Cabe aqui ressaltar que não se teve acesso ao número total de demitidos no Estado de Minas Gerais no período dos programas de adequação de quadros - somente para todo o país, em torno de 50 mil postos de trabalho. Esses dados apresentados servem apenas para ilustrar que a política continuou, de uma forma menos agressiva, mas continuou.

Mais recentemente, já no ano de 2001, uma nova forma de adequação de quadros se instalou a partir dos chamados atos de gestão. As demissões por meio desses atos de gestão administrativa, sem justa causa e sem instauração de inquérito administrativo, conforme a instrução interna, ocorreriam se ficasse evidenciado, após avaliação formal pelo comitê de administração da dependência, tratar-se de funcionário ineficiente, improdutivo ou sem condições de ajustamento à filosofia da empresa. Criava-se, assim, a possibilidade de demissões de trabalhadores que não correspondessem às expectativas de produtividade da empresa. Na realidade, o demitido poderia ou não ser substituído por outro.

\section{O absenteísmo}

No período entre 1998 e 2003, ocorreram 6.445 afastamentos por licença-saúde, totalizando 302.893 dias de afastamento. Os distúrbios osteomusculares, de longe o maior contingente de acometimento na população de trabalhadores, foram responsáveis por aproximadamente 56\% dos 302.893 dias de afastamentos e $23 \%$ do total de eventos, que corresponderam a 6.445 afastamentos (Tabela 1).

A empresa foi notificada 25 vezes versando sobre o assunto ergonomia no período do estudo, sendo que, $76 \%$ delas ocorreram até o ano 2000. Em relação às Comunicações de Acidentes de Trabalho (CAT), das 1.215 emitidas entre 1993 e 2003, aproximadamente $77 \%$ (940) foram por DORT/LER (Tabela 2).

O grupamento dos transtornos mentais e comportamentais representou a segunda maior causa de afastamentos entre os bancários dessa empresa no período de 1998 a 2003. Representaram $19,28 \%$ do total de dias de afastamento (302.893). Quanto ao número de eventos, representou $23 \%$ do total de 6.445 afastamentos (Tabela 1).

No tocante aos subgrupos dessas morbidades que predominaram no período do estudo, os transtornos do humor foram responsáveis 
Número de afastamentos e quantidade de dias, por grupamentos da Classificação Estatística Internacional de Doenças e Problemas Relacionados à Saúde 10a Revisão (CID-10) 14 em um banco estatal. Minas Gerais, Brasil (1998 a 2003)

\begin{tabular}{|c|c|c|c|c|}
\hline \multirow[t]{2}{*}{ CID-10 } & \multicolumn{2}{|c|}{ Afastamentos } & \multicolumn{2}{|c|}{ Dias de afastamento } \\
\hline & $\mathrm{n}$ & $\%$ & $\mathbf{n}$ & $\%$ \\
\hline I. Doenças infecciosas e parasitárias (A00-B99) & 228 & 3,54 & 3.692 & 1,22 \\
\hline II. Neoplasias (tumores) (CO0-D48) & 175 & 2,72 & 6.418 & 2,12 \\
\hline III. Doenças do sangue e dos órgãos hematopoéticos e alguns transtornos imunitários (D50-D89) & 10 & 0,16 & 66 & 0,02 \\
\hline IV. Doenças endócrinas, nutricionais e metabólicas (E00-E90) & 64 & 0,99 & 2.965 & 0,98 \\
\hline V. Transtornos mentais e comportamentais (F00-F99) & 991 & 15,38 & 58.395 & 19,28 \\
\hline VI. Doenças do sistema nervoso (G00-G99) & 149 & 2,31 & 7.523 & 2,48 \\
\hline VII. Doenças do olho e anexos (H00-H59) & 209 & 3,24 & 2.168 & 0,72 \\
\hline VIII. Doenças do ouvido e da apófise mastóide (H60-H95) & 66 & 1,02 & 601 & 0,20 \\
\hline IX. Doenças do aparelho circulatório (I00-199) & 278 & 4,31 & 7.160 & 2,36 \\
\hline X. Doenças do aparelho respiratório (J00-J99) & 890 & 13,81 & 4.109 & 1,36 \\
\hline XI. Doenças do aparelho digestivo (KOO-K93) & 384 & 5,96 & 3.352 & 1,11 \\
\hline XII. Doenças da pele e do tecido subcutâneo (L00-L99) & 85 & 1,32 & 1.830 & 0,60 \\
\hline XIII. Doenças do sistema osteomuscular e do tecido conjuntivo (M00-M99) & 1.482 & 22,99 & 168.697 & 55,70 \\
\hline XIV. Doenças do aparelho geniturinário (N00-N99) & 289 & 4,48 & 5.017 & 1,66 \\
\hline XV. Gravidez, parto e puerpério (О00-О९9) & 213 & 3,30 & 10.068 & 3,32 \\
\hline XVI. Algumas afecções originadas no período perinatal (P00-P96) & 1 & 0,02 & 457 & 0,15 \\
\hline XVII. Malformações congênitas, deformidades e anomalias cromossômicas (Q00-Q99) & 11 & 0,17 & 378 & 0,12 \\
\hline VXIII. Sintomas, sinais e achados anormais de exames clínicos e de laboratório não & 176 & 2,73 & 1.659 & 0,55 \\
\hline \multicolumn{5}{|l|}{ classificados em outra parte (R00-R99) } \\
\hline XIX. Lesões, envenenamentos e algumas outras conseqüências de causas externas (S00-T98) & 454 & 7,04 & 12.550 & 4,14 \\
\hline XX. Causas externas de morbidade e de mortalidade (V01-Y98) & 3 & 0,05 & 42 & 0,01 \\
\hline XXI. Fatores que influenciam o estado de saúde e o contato com os serviços de saúde (ZO0-Z99) & 287 & 4,45 & 5746 & 1,90 \\
\hline Total & 6.445 & 100,00 & 302.893 & 100,00 \\
\hline
\end{tabular}

por aproximadamente $55 \%$ do número de dias de afastamentos e os transtornos neuróticos relacionados ao estresse e transtornos somatoformes por quase $32 \%$ (Tabela 2). Essas doenças são intimamente vinculadas à organização do trabalho, porém não reconhecidas pela empresa como originadas nela e, portanto, sem a devida emissão de CAT. Caso reconhecidas, o número de CAT seria bem superior àquele relatado.

Considerando-se as prevalências referentes as duas morbidades que mais acometeram esse grupo de trabalhadores, constatou-se que elas não se distribuíram homogeneamente no período estudado, porém houve declínio anual da prevalência dos distúrbios osteomusculares no período, chegando em 2003 com queda de 1,86 vez em relação a 1998. Quanto aos transtornos mentais e do comportamento, houve comportamento inverso, com aumento de 1,24 vez no período. Estes, além desse comportamento inverso, suplantaram os anteriores em 2003 (Tabela 3). Em 1998, a prevalência de afastamentos pelos DORT era de 34,47 , caindo para 18,54 em
2003. Em contrapartida, a prevalência dos transtornos mentais passou de 16,59 em 1998 para 20,94 em 2003.

No seguimento desse período, entre 2004 e 2005, os distúrbios osteomusculares passaram a representar $19 \%$ do número de afastamentos e os transtornos mentais e do comportamento por aproximadamente $25 \%$.

As aposentadorias por invalidez, por acidentes e doenças do trabalho ocorridas entre $1993 \mathrm{e}$ 2003 - 417 das 421 aposentadorias (99\%) - foram por DORT. Nesse período, tem-se dados somente sobre aposentadorias por invalidez oriundas de doenças do trabalho, que, no caso dessa empresa, incluiu somente casos de DORT (os transtornos mentais e comportamentais não foram incluídos nas aposentadorias por invalidez decorrentes do trabalho). Essas morbidades geram quase sempre longos afastamentos, superiores a noventa dias. Com a efetivação dessas aposentadorias, houve grande redução no número de dias de afastamentos. Em 1998, foram 100.765 dias de afastamentos e, em 2003, 24.974 dias. 
Distribuição dos acidentes de trabalho em um banco estatal. Minas Gerais, Brasil (1998 a 2003).

\begin{tabular}{lcccc}
\hline Ano & Acidente de & Número de casos de acidentes de trabalho \\
trabalho típico & $\begin{array}{c}\text { Acidente } \\
\text { de trajeto } \\
\text { profissional }\end{array}$ & Total \\
\hline 1993 & 3 & 8 & 48 & 59 \\
1994 & 12 & 6 & 110 & 128 \\
1995 & 12 & 9 & 143 & 164 \\
1996 & 15 & 7 & 189 & 211 \\
1997 & 10 & 4 & 195 & 209 \\
1998 & 22 & 7 & 71 & 100 \\
1999 & 11 & 3 & 43 & 57 \\
2000 & 13 & 3 & 48 & 64 \\
2001 & 38 & 3 & 37 & 78 \\
2002 & 37 & 5 & 34 & 76 \\
2003 & 39 & 8 & 22 & 69 \\
Total & 212 & 63 & 940 & 1.215 \\
\hline
\end{tabular}

Tabela 3

Prevalência por mil trabalhadores, número e dias de afastamentos por licença-saúde, conforme os grupamentos V e XIII da Classificação Estatística Internacional de Doenças e Problemas Relacionados à Saúde, 10ạ Revisão (CID-10) 14, em um banco estatal. Minas Gerais, Brasil (1998 a 2003).

\begin{tabular}{|c|c|c|c|c|c|c|}
\hline \multirow[t]{3}{*}{ Anos } & \multicolumn{6}{|c|}{ Grupamentos da CID-10 } \\
\hline & \multicolumn{3}{|c|}{ V. Transtornos mentais e comportamentais } & \multicolumn{3}{|c|}{ XIII. Doenças do sistema osteomuscular e do tecido conjuntivo } \\
\hline & $\mathbf{n}$ & População & Prevalência/mil & $\mathbf{n}$ & População & Prevalência/mil \\
\hline 1998 & 119 & 7.021 & 16,95 & 242 & 7.021 & 34,47 \\
\hline 1999 & 107 & 7.517 & 14,23 & 224 & 7.517 & 29,80 \\
\hline 2000 & 137 & 7.566 & 18,11 & 189 & 7.566 & 24,98 \\
\hline 2001 & 222 & 7.558 & 29,37 & 386 & 7.558 & 51,07 \\
\hline 2002 & 249 & 7.411 & 33,60 & 302 & 7.411 & 40,75 \\
\hline 2003 & 157 & 7.499 & 20,94 & 139 & 7.499 & 18,54 \\
\hline Total & 991 & - & - & 1.482 & - & - \\
\hline
\end{tabular}

Já no período em que estão disponíveis os dados sobre todas as aposentadorias por invalidez permanente (doenças do trabalho e outras), dentre aquelas homologadas no período entre $2001 \mathrm{e}$ 2003, $61(55,45 \%)$ aconteceram pelo mesmo grupo de morbidades (DORT). Há um incremento no número de aposentadorias por outros motivos que não morbidades relacionadas aos distúrbios osteomusculares, conforme se pode notar na Tabela 4. Em 2001, os distúrbios osteomusculares representavam $77,5 \%$ das aposentadorias, caindo para $51 \%$ em 2003. As aposentadorias por outras morbidades aumentaram de $22,5 \% \mathrm{em}$ 2001 para $49 \%$ em 2003. Os registros de aposen- tadorias do período indicam que, praticamente todas aquelas que não decorreram de distúrbios osteomusculares, se deveram aos transtornos mentais e do comportamento.

Os dados apresentados também chamam a atenção para outros tipos de morbidades, como os problemas respiratórios e as lesões, envenenamentos e algumas outras conseqüências de causas externas, aqui não analisados tendo em vista serem compostos basicamente por eventos agudos e de curta duração (até cinco dias) e também por não estarem vinculados, pelo menos em princípio, com a forma com que o trabalho é organizado. 
Número de aposentadorias e total de dias de afastamentos dos trabalhadores aposentados por invalidez permanente, em um banco estatal. Minas Gerais, Brasil (2001 a 2003)

\begin{tabular}{|c|c|c|c|c|c|c|}
\hline \multirow[t]{3}{*}{ Anos } & \multicolumn{3}{|c|}{ Número de aposentadorias } & \multicolumn{3}{|c|}{ Número de dias de afastamentos referente aos aposentados } \\
\hline & DORT & Outros & Total & DORT & Outros & Total \\
\hline & n (\%) & n (\%) & & n (\%) & n (\%) & \\
\hline 2001 & $31(77,5)$ & $9(22,5)$ & 40 & $14.018(77,5)$ & $4.295(23,0)$ & 18.313 \\
\hline 2002 & $9(31,0)$ & $20(69,0)$ & 29 & $11.675(63,0)$ & $6.967(37,0)$ & 18.642 \\
\hline 2003 & $21(51,0)$ & $30(49,0)$ & 41 & $15.447(77,0)$ & $4.608(23,0)$ & 20.055 \\
\hline Total & $61(55,0)$ & $49(45,0)$ & 110 & $41.140(72,0)$ & $15.870(28,0)$ & 57.010 \\
\hline
\end{tabular}

DORT: distúrbios osteomusculares relacionados ao trabalho.

\section{Discussão}

As transformações na organização do trabalho experimentadas pelo setor bancário foram, inicialmente, lentas e graduais. Entretanto, com o uso intensivo das novas tecnologias de automação bancária e de novas formas de gestão do trabalho, essas mudanças passaram a ocorrer mais velozmente. Os trabalhadores bancários passaram a submeter-se à velocidade, auxiliados pelas novas tecnológicas, necessitando, com isto, adaptar-se às mudanças ${ }^{13}$.

$\mathrm{O}$ que diferenciou a reestruturação nos bancos públicos, particularmente no analisado neste estudo, foi a velocidade, neste caso mais tardia, além da ruptura de uma cultura de convivência em uma empresa onde a regra geral, tida como código de conduta (nunca escrito e aplicado durante décadas), era a de que quem entrava na empresa somente sairia para usufruir a aposentadoria. Foi também um processo sem a devida transparência, não discutido com os trabalhadores nem com seus órgãos representativos, em que não houve negociação por parte da empresa e os critérios não foram seguidos, imperandose a subjetividade na escolha dos excedentes. Os trabalhadores não tiveram muitas opções.

A violência do desmonte no setor bancário estatal foi exemplar no banco analisado, no qual os planos e programas destinados a racionalizar e otimizar despesas e pessoal expressaram-se de maneira inequívoca nas relações laborais ali estabelecidas, que reproduzem as táticas gerenciais de controle e intensificação do trabalho praticadas nos grandes grupos bancários privados 16. A série de mudanças e planos de ajustes que enxugaram o quadro de pessoal desmistificou essa cultura e levou a uma profunda deterioração das relações de trabalho. Para Lima 17, nos bancos estatais, além dos problemas relativos ao processo de enxugamento de quadros, houve a quebra de um pacto implícito de estabilidade.

A seqüência de planos de modernização organizacional, tecnológica e administrativa implementados na segunda metade dos anos 90, complementou os programas de ajustes que previam uma eficiente utilização da força de trabalho a partir de medidas como realocação de trabalhadores considerados em excesso nas dependências, incentivo a aposentadorias e licença-interesse e programas de demissão no interesse do serviço e incentivada 10 . Uma política voltada para a contenção do quadro de pessoal - inicialmente por meio da adequação e depois apenas com reposição. O banco estatal objeto deste estudo demitiu cerca de 50 mil trabalhadores entre 1995 e 1998. A política de desligamentos e contratações que se seguiu aos planos de adequação de quadros foi de mera reposição de efetivo.

Reflete-se sobre a possibilidade de que uma pressão muito forte para o enxugamento de quadros durante o processo de seleção dos elegíveis para desligamento poderia ou não influenciar no estado de saúde dos trabalhadores. O clima de insegurança então instaurado poderia ser um facilitador de adoecimento dos trabalhadores? Aliados à intensificação do trabalho advinda da redução de funcionários, processos de doenças ocorreram gerando problemas de LER ou DORT 18. Conhecendo-se o absenteísmo em um dado setor, teremos possíveis indicadores da relação causal e de seus efeitos deletérios à saúde dos trabalhadores, das mudanças tecnológicas e organizacionais implementadas nos locais de trabalho 19 .

Houve redução atípica de $187 \%$ no número de dias de afastamentos entre os anos de 1998 e 1999. Muitos dos elegíveis para se demitirem ou serem demitidos faziam parte do grupo de trabalhadores com grandes afastamentos 8 . 
Outra forma de redução de quadro, principalmente redução de absenteísmo, ocorreu em relação às aposentadorias. Com a efetivação das aposentadorias dos afastados por doença ocupacional, houve grande redução no número de dias de afastamentos. Esse número caiu, em 1998, para 100.765 dias e, em 2003, para 24.974 dias. O impacto dessa diminuição para cerca de um quarto, fez-se sentir claramente no absenteísmo, com a efetivação dessas aposentadorias por invalidez 8 .

Dos afastamentos por licença-saúde ocorridos no período do estudo, grande parte decorreu de morbidades muito comumente relacionadas à forma como o trabalho é organizado, tais como os DORT e os transtornos mentais e comportamentais. Os DORT corresponderam a aproximadamente 23\% (1.482) dos 6.445 afastamentos do período e em torno de $56 \%$ do número de dias de afastamentos (168.697).

Os transtornos mentais e comportamentais corresponderam a aproximadamente $15 \%$ dos afastamentos (991) e 19\% do total de dias de afastamentos (58.395). Houve um declínio no número de aposentadorias por DORT e incremento no número das mesmas por outras morbidades, principalmente os transtornos mentais e do comportamento. Silva \& Pinheiro 19,20 indicam uma tendência na mudança do perfil de absenteísmo no setor bancário, com os distúrbios osteomusculares sendo superados pelos transtornos mentais e do comportamento.

Conforme relatado na literatura, houve como repercussões do processo de reestruturação produtiva implementado nos bancos um aumento significativo no número de doenças já conhecidas, como as LER e a fadiga psíquica, e de outras menos conhecidas, como a síndrome do pânico, a síndrome da fadiga crônica, além do aumento de quadros como o alcoolismo, depressão ou ansiedade 9,11,12,17,21,22

As políticas adotadas pela empresa para a adequação de quadros tiveram forte impacto na redução do efetivo em pequeno espaço de tempo. O PDV e os PAQ e de contratação de pessoal tornaram-se elementos importantes à compreensão de como a reestruturação produtiva do trabalho afetou os modos de trabalhar e de ser dos trabalhadores bancários 13 .

Essa reflexão pareceu necessária na construção do conhecimento relativo à saúde do trabalhador bancário, principalmente naquele concernente ao efeito deletério que as mudanças ocorridas nas últimas décadas na organização do trabalho causaram.

Apesar disso, grandes foram as limitações do estudo, principalmente quanto ao conjunto de dados disponíveis para avaliação. As análises foram indiretas, por meio daquilo que se apresen- tou disponível. Usaram-se dados secundários, originados na própria empresa, para um curto período histórico. A burocracia para conseguilos foi grande e não existe maior interesse da empresa em que sejam conhecidos. Os eventos analisados (afastamentos e número de dias de afastamentos) necessitam de mais dados para permitir avaliações estatísticas mais objetivas. As informações também não refletem a precisa magnitude e gravidade do processo de saúde e doença entre os bancários, mas, apesar de tudo, o estudo é apresentado e pode servir de ponto de partida para novas discussões que, certamente, se fazem necessárias. Observe-se também que este estudo faz parte de um projeto maior que se desmembrou em outras publicações.

\section{Conclusões}

Na empresa analisada, o processo de reestruturação produtiva esteve associado à redução dos postos de trabalho a uma mudança no perfil de adoecimento. Esse processo se utilizou do medo do desemprego para rebaixar salários, ampliar a disciplina e a insegurança no trabalho. Nela, houve a redução de mais de cinqüenta mil postos de trabalho em todo o país durante os programas de ajustes de quadro presentes na reestruturação produtiva.

O processo de ajuste de quadros da empresa foi particularmente intenso, realizado em curto período e quebrando um acordo tácito de estabilidade, até então constatada.

Nota-se também uma mudança no perfil das atividades exercidas pelo bancário, que passa a ser um funcionário polivalente, além de um excelente vendedor. A manutenção do emprego em tempos de reestruturação produtiva se constitui no principal motivo para tolerar o trabalho mais intenso, mais precário e desregulamentado. $\mathrm{O}$ bancário da empresa estudada foi particularmente afetado por esse processo, conforme se pode notar na descrição do processo na empresa.

O absenteísmo na empresa, isto é, o número de dias de afastamento no período do estudo (302.893 dias), associado ao número de afastamentos (6.445 eventos), expressa um pouco do impacto desse processo na saúde e na vida laboral dos trabalhadores da empresa: uma média de aproximadamente 47 dias por afastamento e de 40 dias por trabalhador (7.499) é bastante considerável.

Este estudo demonstrou o peso que os grupamentos de morbidades, particularmente os distúrbios osteomusculares e transtornos mentais e comportamentais, tiveram no absenteísmo dos trabalhadores. Uma tendência à inversão do per- 
fil predominante também ocorreu no período, com indicativo de que os primeiros serão superados pelos segundos.

A literatura consultada confirma e realça esses achados. Deve-se ressaltar que o período de estudo é posterior ao momento mais intenso da reestruturação produtiva, porém lhe é seguinte e pode-se considerá-lo como sendo o período em que os efeitos se fizeram sentir mais intensamente.

\section{Resumo}

A reestruturação produtiva no setor financeiro brasileiro instalou-se por meio do trinômio demissões em massa, automação e terceirização, além de processos de reengenharia empresarial, com redução de níveis hierárquicos, flexibilização e polivalência de funções. O bancário, para se adaptar e resistir às exigências, aumentou seu nível de escolaridade, tornou-se polivalente e exímio vendedor, submetendo-se à precariedade das condições de trabalho, aumento da carga de serviços, longas jornadas e baixos salários. Este trabalho teve como objetivo avaliar o processo de reestruturação produtiva em um banco público do Estado de Minas Gerais, Brasil, e seus possíveis impactos na saúde de seus trabalhadores. Analisou-se também o absenteísmo no periodo entre 1998 e 2003, quando houve maior desenvolvimento de doenças, como lesão por esforço repetitivo/distúrbios osteomusculares relacionados ao trabalho (LER/DORT) e os distúrbios mentais e comportamentais, sendo responsáveis, respectivamente, por $56 \%$ e $19 \%$ do número de dias de afastamentos. $O$ processo continuou até os dias atuais, com uma política restritiva de contratações. Novos estudos se fazem necessários para a continuidade desta análise e para confirmar os resultados encontrados.

Transtornos Traumáticos Cumulativos; Saúde Ocupacional; Saúde Mental
A continuidade deste estudo se faz necessária, não só para melhor avaliação dos prováveis efeitos da reestruturação produtiva sobre os trabalhadores dessa empresa, mas também porque se acredita que esse processo não terminou - ele apenas mudou seus rumos conforme as mudanças ocorridas no próprio capitalismo, que se reestrutura e se reinventa a todo instante.

\section{Colaboradores}

L. S. Silva participou na revisão de literatura, elaboração da metodologia, análise e redação final do artigo. T. M. M. Pinheiro contribuiu na análise e redação final do artigo. E. Sakurai colaborou na elaboração da metodologia e revisão do final do artigo. 


\section{Referências}

1. Antunes R. Os caminhos da liofilização organizacional: as formas diferenciadas da reestruturação produtiva no Brasil. Idéias 2002/2003; 9/10:13-24.

2. Pochmann M. O trabalho sob fogo cruzado: exclusão, desemprego e precarização no final do século. São Paulo: Editora Contexto; 1999.

3. Harvey D. Condição pós-moderna. São Paulo: Edições Loyola; 2001

4. Departamento Intersindical de Estatística e Estudos Socioeconômicos. Linha bancários. Mudanças no perfil da categoria bancária: ocupação, gênero, escolaridade e faixa etária. São Paulo: Departamento Intersindical de Estatística e Estudos Socioeconômicos; 1997.

5. Silva JB. A face privada de um banco público: os experimentos flexíveis no Banco do Brasil. In: Antunes R, organizador. Riqueza e miséria do trabalho no Brasil. 1 ${ }^{a}$ Ed. São Paulo: Boitempo Editora; 2006. p. 207-36.

6. Laranjeira SMG. Reestruturação produtiva no setor bancário: a realidade dos anos 90. Educação \& Sociedade 1997; ano XVIII, no ${ }^{\circ} .61$.

7. Departamento Intersindical de Estatística e Estudos Socioeconômicos. Linha bancários. Terceirização e reestruturação produtiva no setor bancário no Brasil. São Paulo: Departamento Intersindical de Estatística e Estudos Socioeconômicos; 1994

8. Silva LS. Perfil do absenteísmo em um banco estatal em Minas Gerais: análise no período 1998 a 2003 [Dissertação de Mestrado]. Belo Horizonte: Universidade Federal de Minas Gerais; 2005.

9. Segnini LRP. Reestruturação produtiva nos bancos no Brasil: desemprego, subcontratação e intensificação do trabalho. Educação \& Sociedade 1999; ano XX, n. 67.

10. Jinkings N. Trabalho e resistência na fonte misteriosa: os bancários no mundo da eletrônica e do dinheiro. Campinas: Editora da Unicamp; 2002.

11. Bourguignon D. Perfil epidemiológico de bancários do BANESTES. In: Anais do Simpósio Saúde Mental e Trabalho Bancário. Vitória: Fundação Jorge Duprat Figueiredo de Medicina e Segurança do Trabalho/Universidade Federal do Espírito Santo/ Sindicato dos Empregados em Estabelecimentos Bancários (Espírito Santo)/Associação dos Representantes de Bancos do Espírito Santo; 1997. p. 4159.
12. Selligman-Silva E. Saúde mental e automação: a propósito de um estudo de caso no setor ferroviário. Cad Saúde Pública 1997; 13 Suppl 2:S95-109.

13. Grisci CLI, Bessi VG. Modos de trabalhar e de ser na reestruturação bancária. Sociologias 2004; 6:160-200.

14. Organização Mundial da Saúde. Classificação estatística internacional de doenças e problemas relacionados à saúde, 10a revisão. 4ạ Ed. São Paulo: Centro Colaborador da OMS para a Classificação de Doenças em Português; 1995.

15. Oficina Internacional del Trabajo. Enciclopedia de salud, seguridad e higiene en el trabajo. v. 1. Madrid: Centro de Publicaciones del Ministerio de Trabajo y Seguridad Social; 1991.

16. Jinkings N. A reestruturação do trabalho nos bancos. In: Antunes R, organizador. Riqueza e miséria do trabalho no Brasil. 1a Ed. São Paulo: Boitempo Editora; 2006. p. 189-204.

17. Lima MEA. Reestruturação produtiva e seus impactos na qualidade de vida dos bancários. In: Anais do Simpósio Saúde Mental e Trabalho Bancário. Vitória: Fundação Jorge Duprat Figueiredo de Medicina e Segurança do Trabalho/Universidade Federal do Espírito Santo/Sindicato dos Empregados em Estabelecimentos Bancários (Espírito Santo)/Associação dos Representantes de Bancos do Espírito Santo; 1997. p. 12-7.

18. Penella I. LER: uma jornada de sofrimento no trabalho bancário [Dissertação de Mestrado]. São Paulo: Universidade de São Paulo; 2000.

19. Silva LS, Pinheiro TMM. Absenteísmo no trabalho: sintoma ou doença? Rev Méd Minas Gerais 2006; 16(1 Suppl 2):S62-6.

20. Silva LS, Pinheiro TMM. Perfil do absenteísmo em um banco estatal em Minas Gerais: análise no período 1998 a 2003. Ciênc Saúde Coletiva; no prelo.

21. Cardoso LS, Brandão JPM, Silva PM, Gonçalves VS, Silva Filho JF. Trabalho e saúde mental no Banco do Brasil. J Bras Psiquiatr 1994; 43:667-72.

22. Borges LH. Sociabilidade, sofrimento psíquico e lesões por esforços repetitivos entre caixas bancários. 1a Ed. São Paulo: Fundação Jorge Duprat Figueiredo de Segurança e Medicina do Trabalho; 2001.

Recebido em 26/Jun/2006

Versão final reapresentada em 30/Abr/2007

Aprovado em 16/Mai/2007 